\title{
Experimental and Analytical Study on Deformation Behavior in Hogging Moment Regions of Composite Beams
}

\author{
Aiming Song $\mathbb{D}^{1,2}$ Qi Luo $\mathbb{D}^{3},{ }^{3}$ Shui Wan $\mathbb{D}^{2},{ }^{2}$ and Zhicong $\mathrm{Li} \mathbb{D}^{4}$ \\ ${ }^{1}$ School of Civil Engineering, Yancheng Institute of Technology, Yancheng 224051, Jiangsu, China \\ ${ }^{2}$ School of Transportation, Southeast University, Nanjing 210096, Jiangsu, China \\ ${ }^{3}$ School of Civil Engineering, Chongqing Jiaotong University, Chongqing 400074, China \\ ${ }^{4}$ Hebei Provincial Communications Planning and Design Institute, Shijiazhuang 050011, Hebei, China \\ Correspondence should be addressed to Qi Luo; qiluo@cqjtu.edu.cn and Shui Wan; 694923928@qq.com
}

Received 10 November 2020; Revised 10 December 2020; Accepted 17 December 2020; Published 30 December 2020

Academic Editor: Zhigang Zhang

Copyright $\odot 2020$ Aiming Song et al. This is an open access article distributed under the Creative Commons Attribution License, which permits unrestricted use, distribution, and reproduction in any medium, provided the original work is properly cited.

\begin{abstract}
The results of an experimental and analytical study on the static and fatigue behavior in steel-concrete composite beams under the hogging moment were presented in this paper, and the structural deformation was discussed cautiously and emphatically. Firstly, the static and fatigue tests on three inverted simply supported beams were conducted. The development of cracks under static loading, the load-deformation curves, and the values of residual deformation under fatigue load were recorded and analyzed in detail. Several meaningful conclusions were obtained from the analysis of experimental results. To study the development laws of residual deformation under fatigue load, the analytical methods of residual midspan deflection and residual rebar strain were proposed, respectively. The limitation and accuracy of the presented models were studied according to the comparison between the prediction and measured results. The calculation values of the proposed models showed good agreement with the test results. Finally, the design recommendations of fatigue deformation were proposed according to the experimental and analytical study on steel-concrete composite beams subjected to hogging moment.
\end{abstract}

\section{Introduction}

In recent years, steel-concrete composite structure was popularly used in varied bridges and public buildings due to the many advantages of concrete and steel [1]. Because of the existence of unfavorable factors such as tension in concrete slabs and compression in steel beams, the hogging moment region of steel-concrete continuous composite beams presents complex nonlinear behavior even under a low static load level. The service performance and durability of the structure are often further affected, under the long-term action of fatigue loads such as moving vehicles, winds, and waves. Then, it is necessary to study the mechanical properties, the development rules of cracks, and the calculation methods of structural deformation and crack width in the hogging moment region of composite beams under static and fatigue loads intensively based on scaled model test, theoretical analysis, and numerical simulation [2-4].
Concrete cracking is a big problem in steel-concrete bridge hogging areas. Crack control of the concrete plate is therefore one of the most critical problems in hogging moment regions close to the intermediate support of the continuous composite bridges. For the construction of a composite bridge, it is an inexpensive and convenient solution that allows cracks to be created within reasonable width limits. A lot of researchers have now paid attention to this aspect, and significant experimental and theoretical studies have been conducted in previous times on the concrete cracking of the composite beams. Shim and Chang [4] suggested a design basis for longitudinal prestress of continuous composite bridges with full-depth precast decks having female-to-female joints through analytical and experimental studies on cracking of the deck. Ryu et al. [5] performed experimental tests on the mechanical behavior of the composite plate beam with prefabricated concrete slabs under hogging moments. 
From the observation of crack distribution, crack spacing, crack widths, and strain of the composite section before and after cracking, crack control in negative moment regions and flexural stiffness of the composite section were analyzed by design equations in proper code. $\mathrm{He}$ et al. [6] showed that the composite beams under the hogging moment configured with stud connectors and PBL connectors, respectively, behaved almost the same in crack width and flexural stiffness through the experimental investigation. Su et al. [7] provided detailed information of the inelastic behavior of the hogging moment zone through two specimens of steel-concrete composite box girder with inclined webs, and it was found that the reinforcement ratio played an important role on the crack control. Sun et al. [8] investigated the effect of longitudinal reinforcement and prestressing on stiffness and cracking of composite beams subjected to negative moment. Meanwhile, a theoretical model was proposed to estimate the effective stiffness, taking into account the tension stiffening effect of concrete cracking. In addition, high-performance concrete materials are more and more widely used in civil engineering $[9,10]$. Due to the excellent crack resistance [11, 12] and fatigue resistance [3], they will have a good prospect of research and application in composite bridge construction.

Until now, there are still no standard and applicable analytical methods for fatigue deformation in the hogging moment regions of steel-concrete composite beams in present design codes. Few researchers have studied the theoretical methods of fatigue deformation. Song et al. [13] presented a calculation model of residual deformation related to static loading in the hogging moment region of composite beams, according to the analytical method of PPC (partially prestressed concrete) beams. Then, a calculation model of the residual deformation connected with fatigue loading in the hogging moment region of composite beams was derived, based on the differential equation of the residual interface slip and the computing method of the residual slip in push-out specimens of studs, but this study did not give the analysis methods for calculating the instantaneous deflection under fatigue loading and the total midspan deflection in the hogging moment region. Besides, the analysis model of residual deflection needs more experimental verification.

Set against the above background, this study aims to investigate the static and fatigue properties of steelconcrete composite beams under the hogging moment. The test program was introduced cautiously, and the test results were observed and analyzed in detail. Based on the existing model for analyzing the residual deformation of composite beams subjected to sagging moment, an analytical formula for evaluating the residual deformation in hogging moment regions was then presented. Meanwhile, based on the calculation method of the nonprestressed rebar under fatigue loading in PPC beams, a calculation model was derived for the evaluation of residual strain in the longitudinal rebar. The accuracy of the presented models was studied through the comparison between the prediction and test results.

\section{Experimental Study}

2.1. Test Specimen and Testing Procedure. To study the static and fatigue properties in negative moment regions, three steelconcrete composite beams numbered SCB1-1, SCB1-2, and SCB1-3 were fabricated and used for the loading test. Specimen SCB1-1 was tested under static loading, and the other two specimens were tested subjected to fatigue loading. Each of the beam models had a span of $3500 \mathrm{~mm}$ and was $3900 \mathrm{~mm}$ long, as shown in Figure 1. The specimens were designed with studs as shear connectors, and the diameter and height were $16 \mathrm{~mm}$ and $90 \mathrm{~mm}$, respectively. Two-row shear studs with the longitudinal and transverse spacings of $100 \mathrm{~mm}$ were welded on the top flange. The static and fatigue experiments were conducted at the structure laboratory of Southeast University. The specimens were reversed, and the test setup is shown in Figure 2. At the interval time of the loading procedure, the cracking formation and the fatigue deformation were cautiously observed by an electronic crack width measurement instrument and a computer through a signal system. The degree of strength of the concrete was C50. The steel plates and rebars, respectively, used were Q345 and HRB400. Table 1 shows the mechanical characteristics of the specimen materials. As for fatigue test, the beam models were the same to the static specimens and were manufactured and held under the uniform conditions. Fatigue loading parameters of the test beam are shown in Table 2 . And $F_{\mathrm{u}}$ is the ultimate bearing capacity of the test beam without fatigue load. Based on the results of the ultimate bearing capacity $F_{\mathrm{u}}$ of specimen SCB1-1 and the laws of crack growth, the maximum fatigue load of the SCB1-2 test beam was set to $25 \% F_{\mathrm{u}}$ (i.e., the median value of the $7 \% F_{\mathrm{u}}$ load and $40 \% F_{\mathrm{u}}$ load at the crack stability stage). The maximum fatigue load for the SCB1-3 test beam is set to $40 \% F_{\mathrm{u}}$ (i.e., the load during the crack stability stage). Loading ratio, loading frequency, and static loading rate were $0.2,2 \mathrm{~Hz}$, and $10 \mathrm{kN} /$ min, respectively. The loading method was sine wave form.

2.2. Analysis of Static Test Results. The major experimental results of beam specimen SCB1-1 are characterized in Table 3 , and the typical crack formation and distribution on the concrete slab under different loading levels is shown in Figure 3. The overall process of crack developing can be defined as four stages. As for stage I, no crack occurred on the concrete slab surface until the applied load increased to $70 \mathrm{kN}$. The width of the initial crack was $0.03 \mathrm{~mm}$ as shown in Figure 3(a), which was difficult to be identified by the naked eyes. In stage II, both the number of cracks and the crack width increased along with the increment of the applied load. When the applied load reached $400 \mathrm{kN}$, the stabilized stage, i.e., stage III of crack developing, was defined, which indicated that the average crack spacing and the number of through cracks remained stationary. Meanwhile, the crack width still increased stably. In stage IV, due to the yielding of the longitudinal reinforcement bar, the width of the major crack shown in Figure 3(c) started to increase at a rather rapid speed until the beam specimen failed, and the final failure mode was compression buckling of the lower flange plate of the steel beam. 

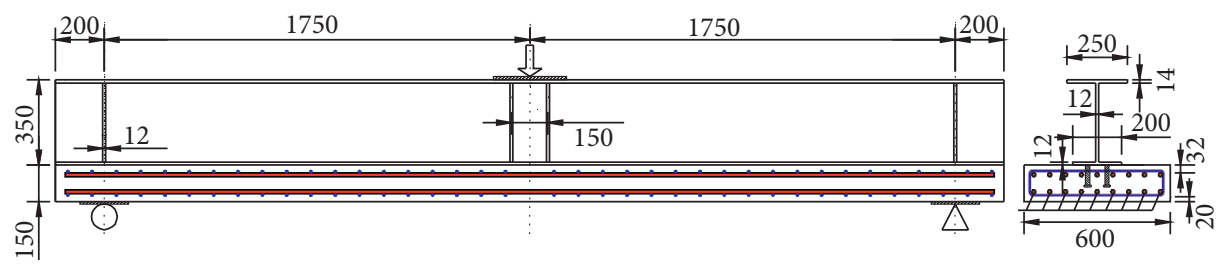

FIGURE 1: Construction details of tested beams (unit: $\mathrm{mm}$ ).

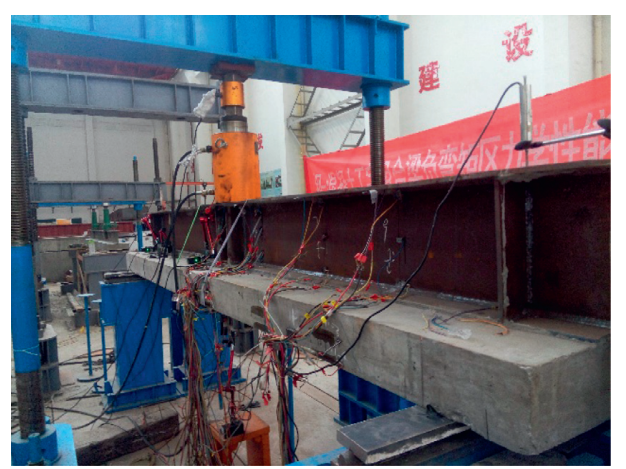

(a)

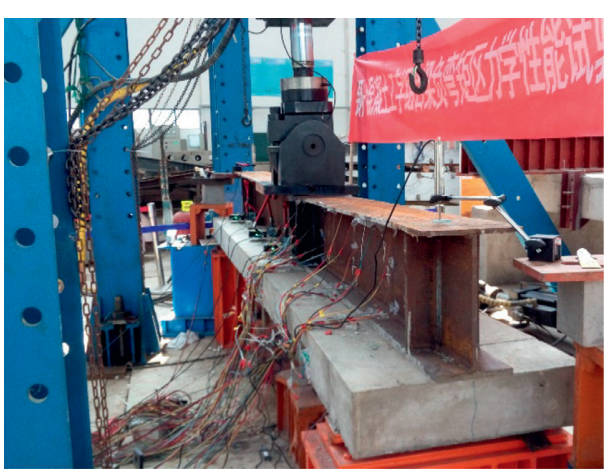

(b)

Figure 2: Loading setup of the specimens: (a) static loading device and (b) fatigue loading device.

TABle 1: Mechanical properties of the specimen materials.

\begin{tabular}{|c|c|c|c|c|c|c|}
\hline $\begin{array}{l}\text { Material } \\
\text { type }\end{array}$ & $\begin{array}{c}\text { Average value of cube } \\
\text { strength }(\mathrm{MPa})\end{array}$ & $\begin{array}{l}\text { Average elastic } \\
\text { modulus }(\mathrm{MPa})\end{array}$ & Material type & $\begin{array}{c}\text { Thickness or } \\
\text { diameter (mm) }\end{array}$ & $\begin{array}{c}\text { Average yield } \\
\text { strength }(\mathrm{MPa})\end{array}$ & $\begin{array}{l}\text { Average ultimate } \\
\text { strength }(\mathrm{MPa})\end{array}$ \\
\hline \multirow{3}{*}{$\begin{array}{l}\text { Concrete } \\
\text { (C50) }\end{array}$} & \multirow{3}{*}{51.2} & \multirow{3}{*}{35400} & $\begin{array}{l}\text { Top flange and } \\
\text { web (Q345) }\end{array}$ & 12 & 443 & 608 \\
\hline & & & $\begin{array}{c}\text { Bottom flange } \\
\text { (Q345) }\end{array}$ & 14 & 391 & 520 \\
\hline & & & Rebar (HRB400) & 16 & 592 & 718 \\
\hline
\end{tabular}

TABLE 2: Fatigue loading parameters of the test beam.

\begin{tabular}{lccccc}
\hline Specimen & Load limit & Loading ratio & Frequency $(\mathrm{Hz})$ & Loading method & Static loading rate $(\mathrm{kN} / \mathrm{min})$ \\
\hline SCB1-2 & $25 \% F_{\mathrm{u}}$ & 0.1 & 2 & Sine wave & 10 \\
SCB1-3 & $40 \% F_{\mathrm{u}}$ & 0.1 & 2 & Sine wave & 10 \\
\hline
\end{tabular}

TABLE 3: Characteristic experimental results of the beam specimen.

\begin{tabular}{cccccccccc}
\hline \multirow{2}{*}{ Specimen } & \multicolumn{2}{c}{ Initial cracking $(70 \mathrm{kN})$} & \multicolumn{2}{c}{$\begin{array}{c}\text { Stabilized cracking } \\
(400 \mathrm{kN})\end{array}$} & \multicolumn{2}{c}{$\begin{array}{c}\text { Reinforcement yield } \\
(700 \mathrm{kN})\end{array}$} & \multicolumn{2}{c}{ Ultimate load (1033 kN) } \\
& $\mathrm{w}_{\text {max }}(\mathrm{mm})$ & $l_{c r}(\mathrm{~mm})$ & $\mathrm{w}_{\text {max }}(\mathrm{mm})$ & $l_{c r}(\mathrm{~mm})$ & $\mathrm{w}_{\text {max }}(\mathrm{mm})$ & $l_{c r}(\mathrm{~mm})$ & $\mathrm{w}_{\text {max }}(\mathrm{mm})$ & $l_{c r}(\mathrm{~mm})$ \\
\hline SCB1-1 & 0.03 & 1 & 0.10 & 105 & 0.20 & 104 & $>1 \mathrm{~mm}$ \\
\hline
\end{tabular}

2.3. Analysis of Fatigue Test Results. No fatigue failures occurred after $250 \times 104$ cycles in SCB1-2 when the fatigue upper limit was equal to $250 \mathrm{kN}$. As for SCB1-3, the fracture of the rebar occurred after about $152 \times 10^{4}$ cycles. Due to the fatigue failure, specimen SCB1-3 had a lower ultimate load of $477.2 \mathrm{kN}$, which was only $46.2 \%$ of SCB11. However, specimen SCB1-3 still had good ductility although the fatigue failure had already occurred. The difference between specimens SCB1-2 and SCB1-3 can also be found in the load-deflection curves as shown in Figures 4(a) and 4(b).

In the experimental tests, strain gauges for measuring reinforcing bars were arranged on longitudinal bars at the midspan section, where the maximum tensile stress probably occurs for simply supported beams under concentrated load in the span center. The gauge locations are shown in 


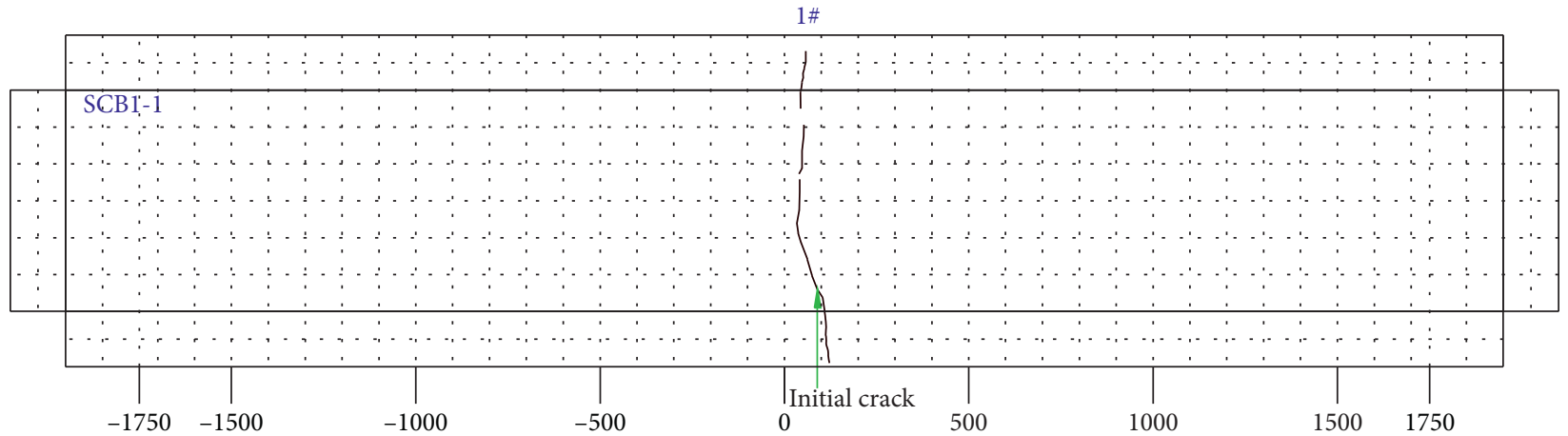

(a)

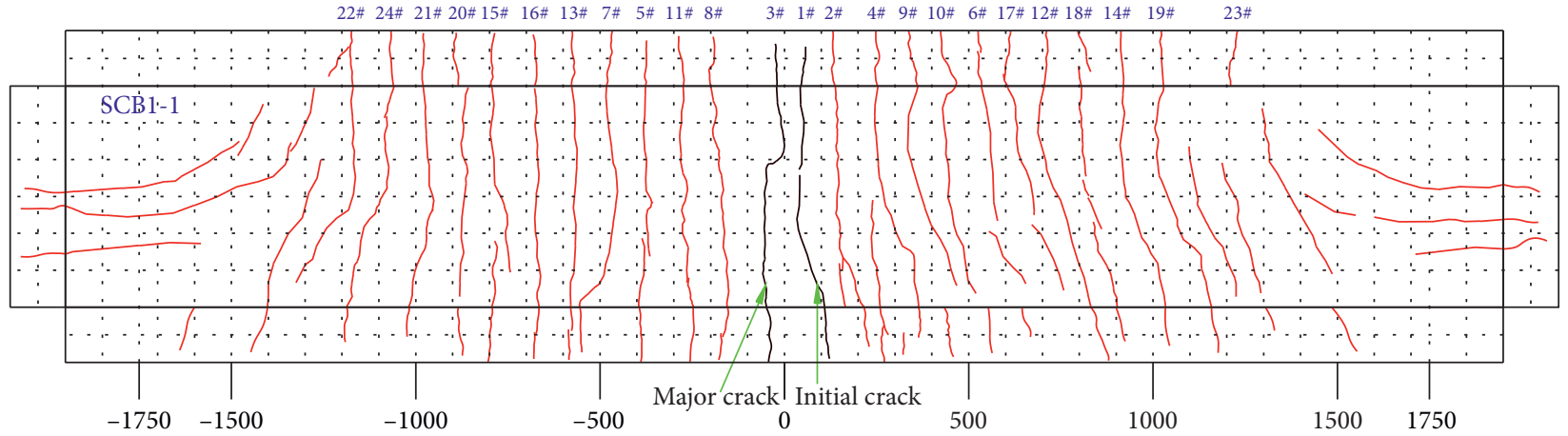

(b)

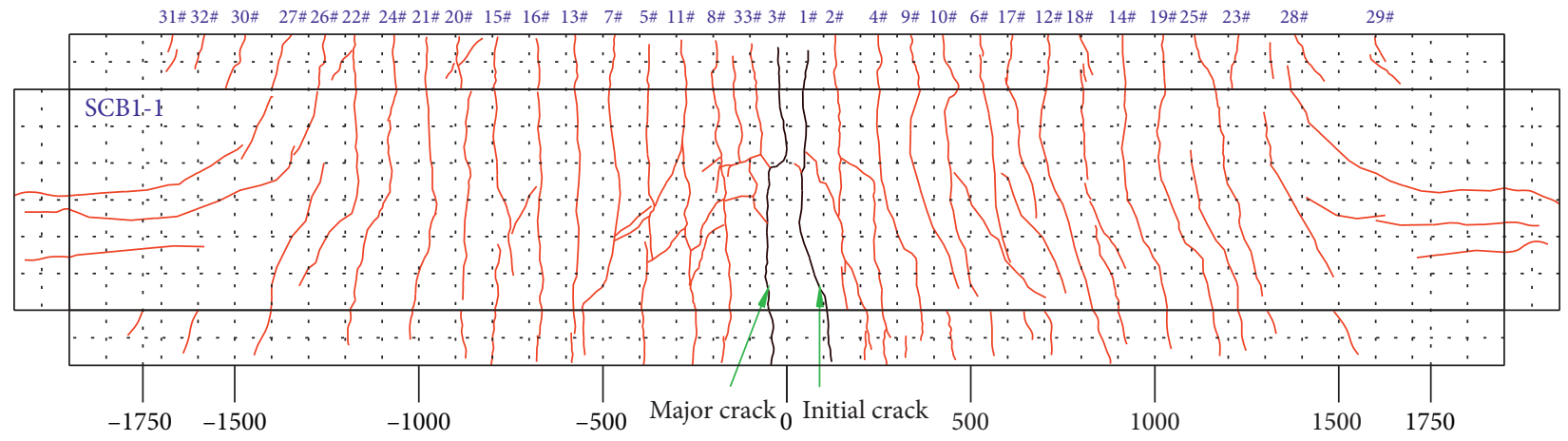

(c)

Figure 3: Crack formation and distribution of the beam specimen under different loading levels (unit: mm): (a) initial cracking load, (b) stabilized cracking load, and (c) ultimate load.

Figure 5. The gauge numbered $0 \#$ was selected, and the reinforcing bar strain was measured and recorded during each intermediate test. The typical strain results of the reinforcing bar in SCB1-2 and SCB1-3 are given in Figures 4(c) and 4(d). The strain jump can be observed from the initial loading stage, and the corresponding load and strain were about $70 \mathrm{kN}$ and $65 \mu$. Similar to the phenomenon in the load-deflection curves of specimens SCB1-2 and SCB1-3, the development law can also be found in the loadstrain curves under fatigue loading. The residual deformation associated with Figure 4 is plotted in Figure 6, where $n$ and $N$ are the number of cycles and the fatigue life, respectively. Also, the curves can be characterized by three stages typically.

\section{Analytical Study}

\subsection{Analytical Model for Calculating the Residual Deflection at Midspan}

3.1.1. Fatigue Life Evaluation of Composite Beams Subjected to Hogging Moment. In this study, the existing method for 


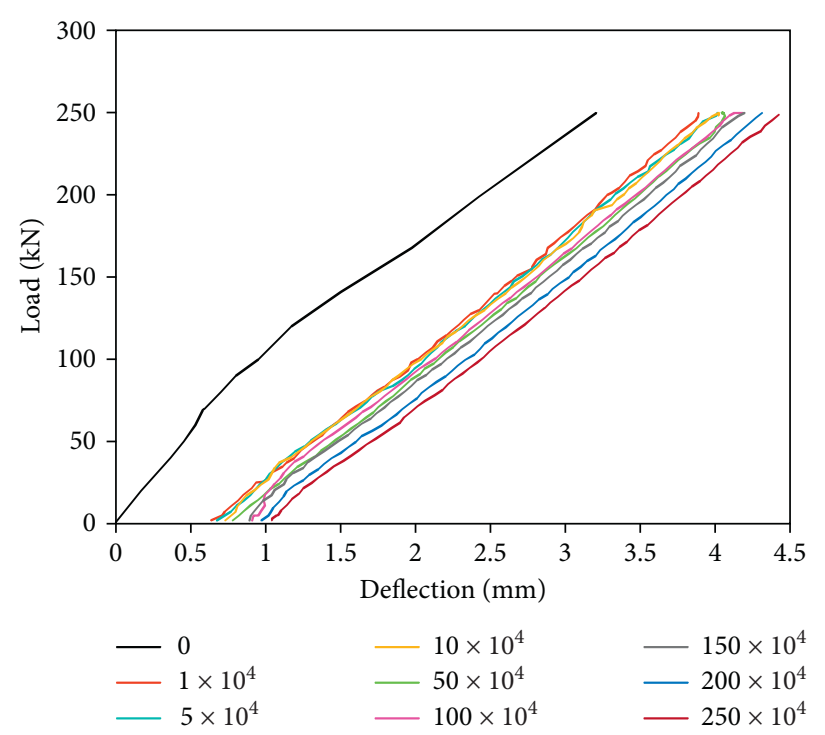

(a)

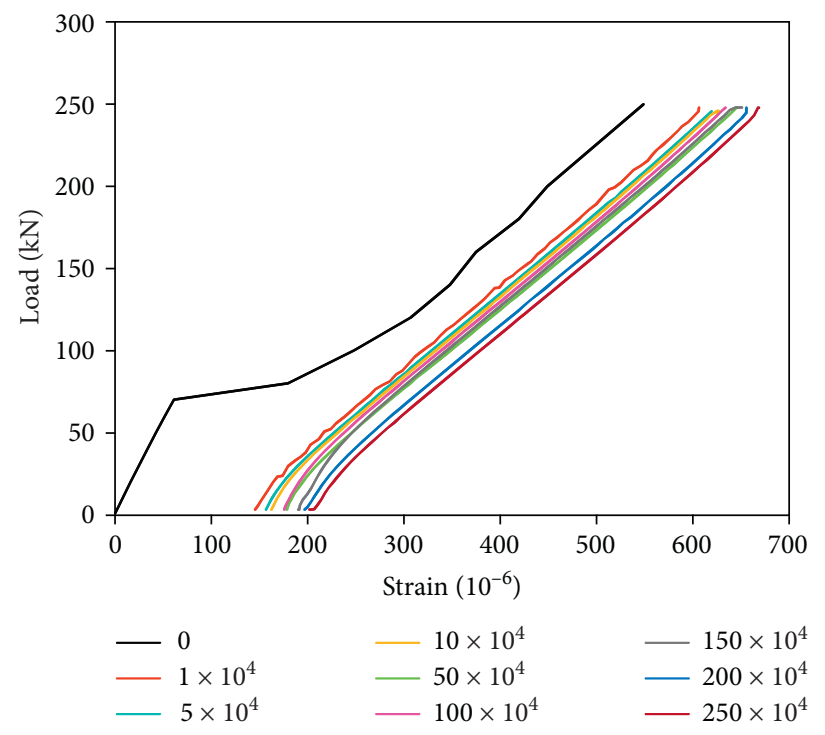

(c)

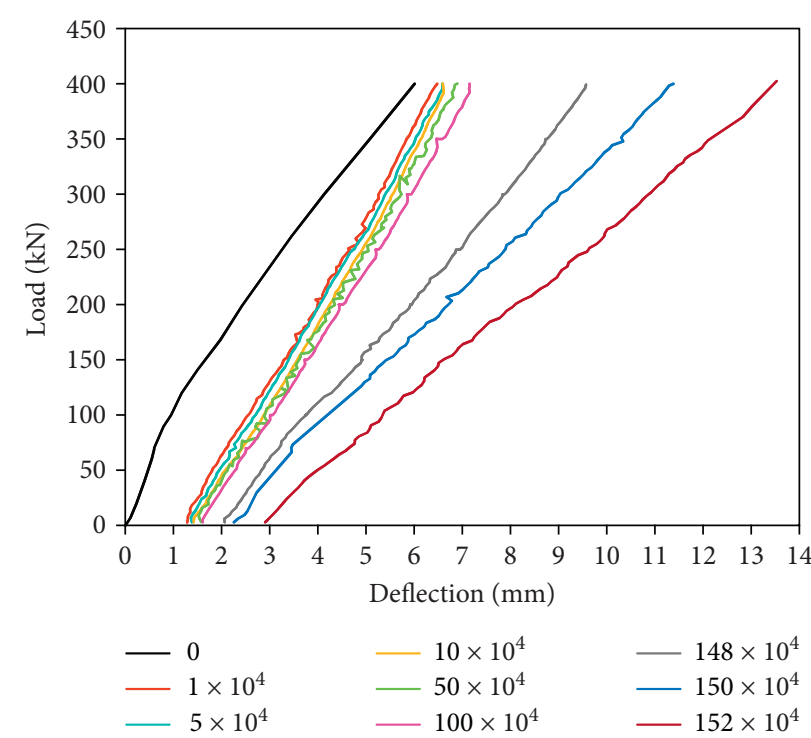

(b)

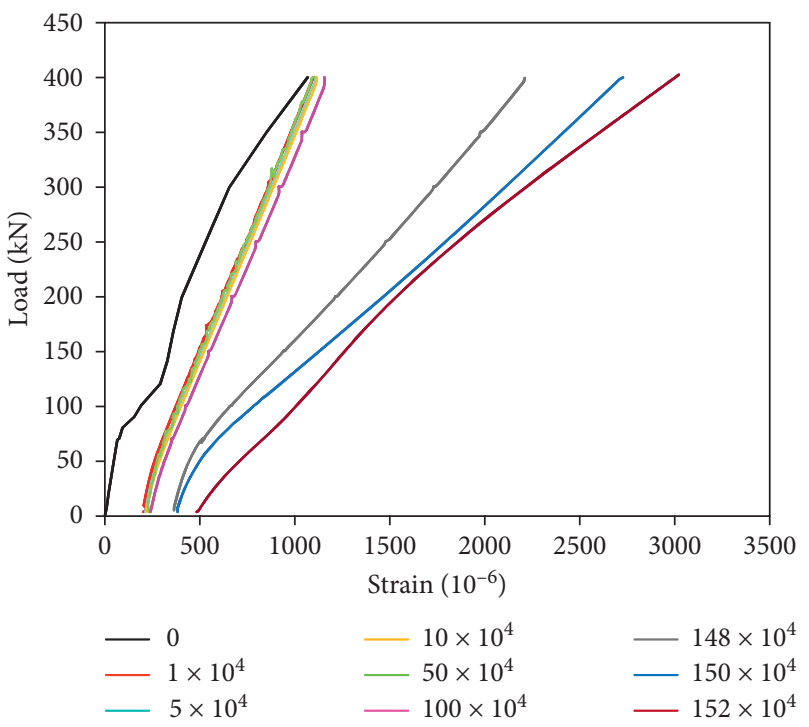

(d)

FIGURE 4: Load-deformation curves after different load cycle numbers: (a) load-deflection curves of SCB1-2, (b) load-deflection curves of SCB1-3, (c) load-strain curves of SCB1-2, and (d) load-strain curves of SCB1-3.

fatigue life of hogging moment regions presented by Song and Wan [13] was employed. Then, the fatigue life in hogging moment regions of composite beams can be given as follows:

$$
\begin{aligned}
\lg N_{f 1}+8 \lg \left(\Delta \tau_{s}\right) & =21.935, \\
\lg N_{f 2}+3 \lg \left(\Delta \sigma_{s}\right) & =12.02, \\
\lg N_{f 3}+3.7928 \lg \left(\Delta \sigma_{r}\right) & =14.7806
\end{aligned}
$$

where $N_{f 1}, N_{f 2}$, and $N_{f 3}$ are the number of fatigue test cycles of the three components, i.e., studs, steel, and rebars and $\Delta \tau_{s}$, $\Delta \sigma_{s}$, and $\Delta \sigma_{r}$ are fatigue strengths of the three components.

Thus, fatigue life $N_{f}$ in hogging moment regions can be given as follows:

$$
N_{f}=\min \left\{N_{f 1}, N_{f 2}, N_{f 3}\right\} .
$$

3.1.2. Calculation Method for Residual Deflection. According to the existing method for plastic slip in shear studs $\left(\delta_{s t d, n}\right)$ [14], a analytical model for calculating the residual deformation $\left(f_{n}\right)$ in sagging moment regions can be given by Wang and Nie [15]:

$$
f_{n}=k \frac{\delta_{\text {std, } n} L}{12 H}
$$

and then the plastic slip of shear studs of $\delta_{s t d, n}$ can be expressed as follows: 


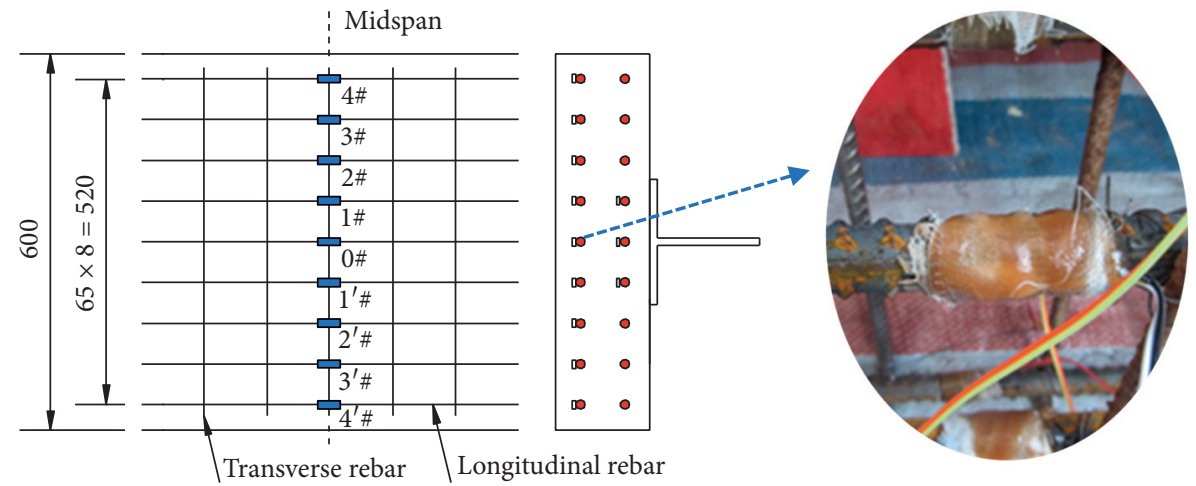

Figure 5: .Locations and arrangement of rebar strain gauges (unit: $\mathrm{mm}$ ).

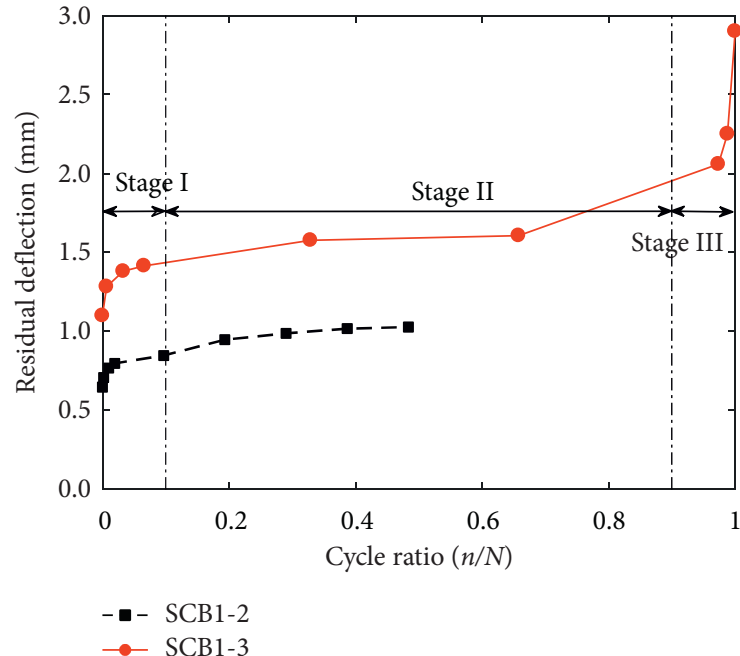

(a)

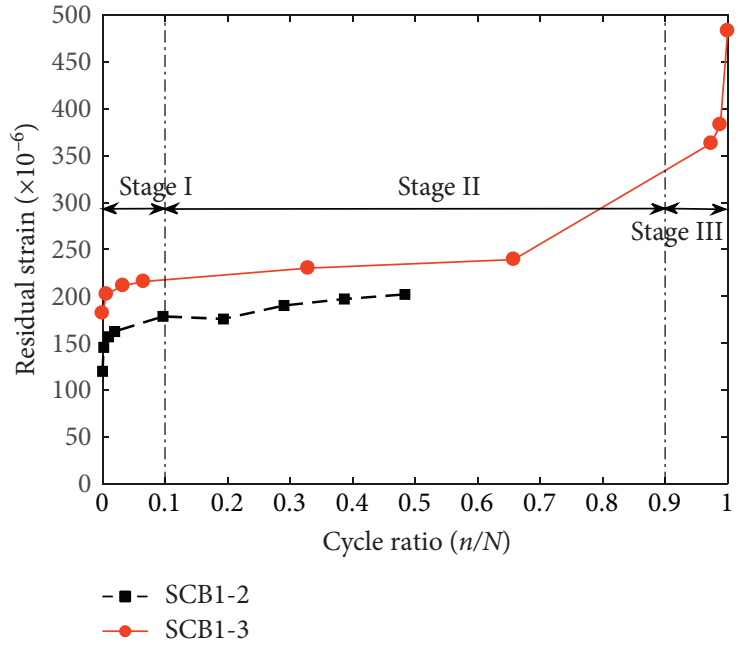

(b)

Figure 6: .Residual deformation versus cycle ratio: (a) residual midspan deflection and (b) residual rebar strain.

$$
\delta_{\text {std }, n}=C_{1}-C_{2} \ln \left(\frac{1}{(n / N)}-1\right) \geq 0, \quad 0<\frac{n}{N}<0.9, \delta_{\text {std }, n}=0, \frac{n}{N}=0
$$

where the parameters $C_{1}$ and $C_{2}$ can be obtained as follows:

$$
\begin{aligned}
C_{1} & =0.104 e^{3.95\left(P_{\max } / P_{u, 0}\right)}, \\
C_{2} & =0.664 \frac{P_{\min }}{P_{u, 0}}+0.029 .
\end{aligned}
$$

In the aforementioned formulas, $k=10.11$ is the undetermined coefficient obtained by data fitting; $L$ is the span of the beam; $H$ is the height of the beam; $n$ is the number of repeated cycles; $N$ is the fatigue life; $P_{u, 0}$ is the ultimate bearing capacity of studs; $P_{\max }$ is the fatigue upper limit of studs; and $P_{\min }$ is the fatigue lower limit of studs.

When the above analytical method in sagging moment regions is employed, the calculation method for predicting the residual deformation value in hogging moment regions was obtained by fitting the measured data in this study. The following relation gives its analytical formulation:

$$
f_{n}=1.04 \frac{\delta_{\text {std }, n} L}{H}
$$

3.1.3. Verification of the Calculation Method. It can be found that the related coefficient $k$ obtained under the sagging moment in [15] was 0.84 , which accounted for about $81 \%$ of that under the hogging moment, and it indicates that the residual deflection in the hogging moment regions will be larger in comparison with sagging moment regions due to the concrete cracking. In order to verify the precision of the proposed method for calculating the deflection of composite beams under the hogging moment, the comparisons were made between the test results and the proposed method, as illustrated in Table 4 . It can be seen that the results calculated by the proposed model had a good agreement with the test results. In addition, the residual deflection will account for more than $30 \%$ of the static deflection caused by the fatigue 
TABLE 4: Comparison between predicted and tested residual deflection values.

\begin{tabular}{|c|c|c|c|c|c|c|c|}
\hline Specimen & $\begin{array}{l}\text { Fatigue life } \\
\left(\times 10^{4}\right) N=N_{f}\end{array}$ & $\begin{array}{c}\text { Static deflection caused by } \\
\text { upper limit } \delta_{u}(\mathrm{~mm})\end{array}$ & $n / N$ & $\begin{array}{l}\text { Residua } \\
\text { Test } \delta_{t}\end{array}$ & $\begin{array}{l}\text { al values }(\mathrm{mm}) \\
\text { Prediction } \delta_{p}\end{array}$ & $\begin{array}{c}\text { Deviation }\left(\delta_{t}-\delta_{p}\right) / \\
\delta_{p} \times 100 \%(\%)\end{array}$ & $\begin{array}{c}\text { Proportion } \\
\delta_{t} / \delta_{u} \times 100(\%)\end{array}$ \\
\hline \multirow{4}{*}{ SCB1-2 } & \multirow{4}{*}{516} & \multirow{4}{*}{3.32} & 0.19 & 0.948 & 0.847 & 11.9 & 28.6 \\
\hline & & & 0.29 & 0.988 & 0.949 & 4.1 & 29.8 \\
\hline & & & 0.39 & 1.018 & 1.065 & -4.4 & 30.7 \\
\hline & & & 0.48 & 1.028 & 1.170 & -12.2 & 31.0 \\
\hline \multirow{2}{*}{ SCB1-3 } & \multirow{2}{*}{152} & \multirow{2}{*}{5.50} & 0.33 & 1.577 & 1.441 & 9.5 & 28.7 \\
\hline & & & 0.66 & 1.607 & 1.750 & -8.2 & 29.2 \\
\hline
\end{tabular}

upper limit under the monotonic loading as listed in Table 4, and this proportion will be larger with the increment of repeated cycles. Therefore, to avoid the unsafe results, the residual deflection caused by fatigue load should be noted.

\subsection{Analytical Model for Predicting the Residual Strain of Longitudinal Reinforcement}

3.2.1. Calculation of Fatigue Stiffness of Studs. For steelconcrete composite structures, the strength or stiffness degradation phenomenon of studs has been investigated under fatigue loading $[16,17]$. The load-slip $\left(P_{n}-\delta_{n}\right)$ relationships of studs under fatigue loading were given in [14], as can be expressed with the following equation:

$$
P_{n}=1.41 P_{u, N}\left(\delta_{n}-\delta_{\text {std }, N}\right), \quad P_{n} \leq 0.8 P_{u, N},
$$

and the static intensity decrease $\left(P_{u, N}\right)$ can be estimated at a specified number of load cycles as follows:

$$
\frac{P_{u, N}}{P_{u, 0}}=0.74 \frac{P_{\max }}{P_{u, 0}}\left(1-\frac{\Delta P}{P_{\max }}\right)+0.54-0.04 \ln \left(\frac{n}{10^{\left(1-\left(P_{\max } / P_{u, 0}\right) /\left(0.1267-0.1344\left(P_{\max } / P_{u, 0}\right)\left(1-\left(\Delta P / 2 P_{u, 0}\right)\right)\right)\right)}-n}\right),
$$

where $\Delta P$ is the range of the cyclic loading, i.e., $\Delta P=P_{\max }-P_{\min }$.

Through a series of experiments and analyses, it was found that the load-slip behavior after $n$ number of repeated cycles was linear for $P_{n} \leq 0.8 P_{u, N}$ [14]. Then, it can be assumed that the residual stiffness of studs under fatigue loading is equivalent to the secant stiffness at the shear connector strength of $P_{\max , n}$ with an equivalent slip of $\delta_{\max , n}$. Thus, the residual stiffness of studs can now be written in the following form:

$$
K_{s, n}=\frac{P_{\max , n}}{\delta_{\max , n}}
$$

\subsubsection{Cycle-Dependent Stress of Reinforcement in the Cracked} Section of Composite Beams. The slip effect at the beam-slab interface has been proved to have a great influence on the mechanical property in the hogging moment regions of continuous composite beams, and an equation proposed by Fan and Nie [18] can be applied to the calculation of residual strain of longitudinal reinforcement which included the slip effect. Then, a cycle-dependent model of reinforcement stress $\left(\sigma_{s}(n)\right)$ in the cracked section can be obtained, while the effect of fatigue loading is incorporated into the equation in [18], namely, the shear-slip stiffness of a single stud shear connector $K_{s}$ and sectional area of reinforcing $A_{r}$ are substituted by $K_{s, n}$ in equation (9) and $A_{s}^{f}(n)$ in equation (13), respectively. The new form of the cycle-dependent model is defined as follows:

$$
\begin{gathered}
\sigma_{s}(n)=\frac{E_{s} A_{s}\left(\varepsilon_{r 0}^{f} I_{0}^{f} y_{0}-\varepsilon_{s}^{f} I_{s} y_{0 r}^{f}\right)}{\left[\left(A_{r}^{f}+A_{s}\right) I_{s}+A_{r}^{f} A_{s} y_{0}^{2}\right] y_{0 r}^{f}}, \\
\varepsilon_{r 0}^{f}=\frac{M y_{0 r}^{f}}{E_{s} I_{0}^{f}}, \\
\varepsilon_{s}^{f}=\frac{4 e^{-\alpha x}\left(e^{\alpha L}-e^{2 \alpha x}\right) \beta M}{\alpha\left(e^{\alpha L}+1\right) L},
\end{gathered}
$$

where $E_{s}$ is Young's modulus of reinforcement; $A_{s}$ is the sectional area of the steel beam; $A_{r}^{f}(n)$ is the effective area of reinforcement after $n$ cycles; $\varepsilon_{r 0}^{f}$ is the reinforcement strain without slip effect at the beam-slab interface under fatigue loading; $\varepsilon_{s}^{f^{f}}$ is the slip strain considering fatigue effect; $M$ is the applied moment acted in the cracked section; $y_{0 r}^{f}$ is the distance from the centroid of reinforcing bars to the neutral axis of the composite section considering fatigue effect; $x$ is the distance from the calculation section to the midspan, and $x=0$ for this study; $\alpha=\sqrt{\left(K_{n} / p E_{s}\right)\left(\left(1 / A_{0}\right)+\left(y_{0}^{2} / I_{s}\right)\right)}$; $\beta=\left(y_{0} / 2 E_{s} I_{s}\right) ; y_{0}=y_{r}+y_{s} ; A_{0}=\left(A_{r}^{f} \cdot A_{s} / A_{r}^{f}+A_{s}\right) ; I_{s}$ is the second moment of area of the steel beam; $y_{r}$ and $y_{s}$ are the distances of the beam-slab interface to the centroid of reinforcing bars and steel beam, respectively; $K_{n}$ is the shear connection stiffness at the beam-slab interface, $K_{n}=n_{s} K_{s, n}$; and $n_{s}$ is the number of shear studs per row.

In the fatigue stress evaluation of equation (10), the effective area of reinforcement after $n$ cycles can be expressed by the following equation [19]: 


$$
A_{r}^{f}(n)=A_{r}\left[1-\frac{n}{N}\left(1-\left(\frac{\sigma_{s}(n)}{f_{s y}}\right)\right)\right],
$$

where $f_{s y}$ is the tensile strength of the reinforcement bar.

By combining equations (10) and (13) and using mathematical software MATLAB, cycle-dependent stress $\sigma_{s}$ $(n)$ and area of reinforcement $A_{r}^{f}(n)$ can then be obtained at the certain repeated number of $n$.

3.2.3. Calculation Method of the Residual Strain. When taking the combination effect of composite beams and fatigue effect of studs into account, an analytical model for estimating the residual strain of nonprestressed reinforcement in PPC beams [19] is employed to the analysis in longitudinal reinforcement of composite beams subjected to hogging moment. The following relation gives the analytical formulation:

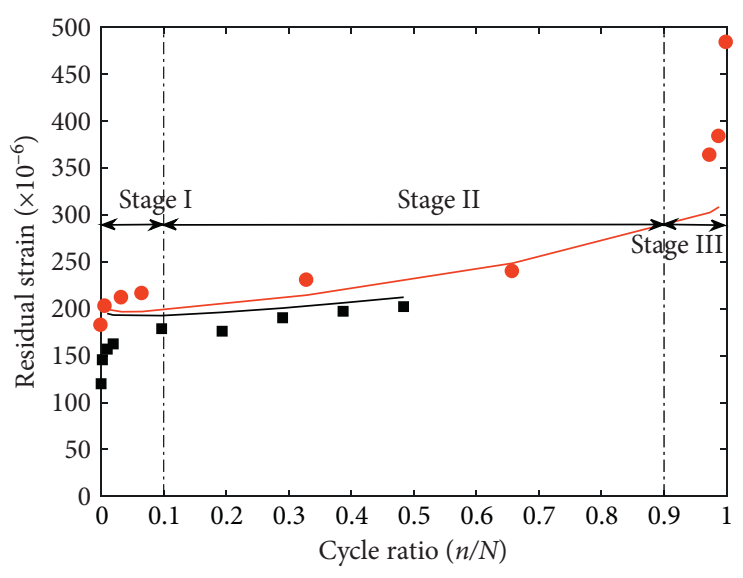

- Test values of SCB1-2 - Test values of SCB1-3 - Prediction of SCB1-2 _ Prediction of SCB1-3

FIgURE 7: .Comparison between predicted and tested residual strain of the rebar.

$$
\varepsilon_{\mathrm{sr}, n}=\frac{\left(\left(A_{r} / 2 A_{r}^{f}\right)+\sqrt{\left(A_{r} / 2 A_{r}^{f}\right)^{2}+\left(2 \pi n_{r} d_{r} E_{c} W_{\mathrm{sr}, n} / n_{0} \beta_{n} f_{\mathrm{ct}, n} A_{r}^{f}\right)}\right) f_{\mathrm{ct}, n}}{2 E_{c}}
$$

and the tensile strength of concrete $\left(f_{c t, n}\right)$ under fatigue loading can be obtained as follows [20]:

$$
f_{\mathrm{ct}, n}=f_{\mathrm{ct}} \cdot 10^{(-0.0023-0.0275 \log n)}
$$

where $n_{r}$ is the number of reinforcement bars in the concrete slab; $d_{r}$ is the diameter of the longitudinal reinforcement bar; $E_{c}$ is Young's modulus of concrete; $E_{s}$ is Young's modulus of the rebar; $n_{0}=E_{s} / E_{c} ; f_{c t}$ is the concrete strength of extension; $W_{s r, n}=0.02 \mathrm{~mm}$ is for the nonrecoverable deformation after unloading; and $\beta_{n}=1$.

3.2.4. Verification of the Calculation Method. To verify the accuracy of the analytical model for estimating the residual strain of longitudinal reinforcement in the hogging moment regions of steel-concrete composite beams under fatigue loading, the predicted curves and experimental results of specimens SCB1-2 and SCB1-3 are shown in Figure 7. It can be seen from Figure 7 that there is a good agreement between the calculation model and experimental results when $0.1<n / N<0.9$, namely, in stage II of the whole development process of residual strain. In addition, a larger deviation occurred in stage I and stage III, which may be ascribed to the discreteness of concrete strength and development of initial microcracks at the beginning of fatigue loading, as well as different failure modes of components and the sharp growth of measured values at the end of fatigue loading.

For further verification of the proposed model quantitatively, the comparison between experimental and calculated residual strain values in stage II $(0.1<n /$ $N<0.9$ ) is listed in Table 5. It can be seen that the deviation values vary from 4.3 to $10.2 \%$. And the results further indicate that the proposed model can be used to predict the residual strain of longitudinal reinforcement in the hogging moment regions of steel-concrete composite beams under fatigue loading. Thus, the proposed model in this study can be a design reference for engineering applications of composite bridges.

3.3. Suggestion for Fatigue Deformation Design. The residual deflection and strain gradually increased due to the fatigue loading, as observed and analyzed in the experimental test. The residual deflection accounted for more than $30 \%$ of the static deflection caused by the fatigue upper limit under the monotonic loading with the increment of repeated cycles (see Table 4). Meanwhile, experimental results showed that the residual stresses in reinforcement can reach about $50 \mathrm{MPa}$ (see Table 5). Moreover, these residual values will become larger with the increase of fatigue cycles. Therefore, the residual deflection and strain should not be ignored in order to correct the accuracy of the calculation formula for the total deformation. When the fatigue load is in the service load stage, the following formulas are suggested to calculate the midspan deflection and reinforcement stress in steel-concrete composite beams subjected to hogging moment:

$$
\begin{aligned}
& f_{t}=f_{0}+f_{N}, \quad\left(0.1<\frac{n}{N}<0.9\right), \\
& \sigma_{s}=\sigma_{s}(n)+E_{s} \varepsilon_{\mathrm{sr}, n}, \quad\left(0.1<\frac{n}{N}<0.9\right),
\end{aligned}
$$

where $f_{0}$ is the elastic deflection in the hogging moment regions of steel-concrete composite beams; $f_{N}$ is the total residual deflection obtained by the analytical model 
TABLE 5: Comparison between predicted and tested residual strain in stage II $(0.1<n / N<0.9)$.

\begin{tabular}{|c|c|c|c|c|c|}
\hline \multirow{2}{*}{ Specimen } & \multirow{2}{*}{ Fatigue life $\left(\times 10^{4}\right) N=N_{f}$} & \multirow{2}{*}{$n / N$} & \multicolumn{2}{|c|}{ Residual strain $\left(\times 10^{-6}\right)$} & \multirow{2}{*}{ Deviation (\%) } \\
\hline & & & Test results & Prediction & \\
\hline \multirow{5}{*}{ SCB1-2 } & \multirow{5}{*}{516} & 0.10 & 178.5 & 192.5 & 7.3 \\
\hline & & 0.19 & 175.9 & 195.9 & 10.2 \\
\hline & & 0.29 & 190.2 & 200.6 & 5.2 \\
\hline & & 0.39 & 197.1 & 206.0 & 4.3 \\
\hline & & 0.48 & 202.0 & 212.1 & 4.7 \\
\hline \multirow{2}{*}{ SCB1-3 } & \multirow{2}{*}{152} & 0.33 & 230.0 & 214.3 & -7.4 \\
\hline & & 0.66 & 239.2 & 248.2 & 3.6 \\
\hline
\end{tabular}

proposed in this paper; and $\sigma_{s}(n)$ is the stress of the reinforcement bar after $n$ cycles.

\section{Conclusions}

In this paper, the static and fatigue properties of steelconcrete composite beams under the hogging moment were studied with experimental tests and analytical models. Through the experimental tests, the crack development process, the fatigue deflection at the midspan, and the fatigue stress of longitudinal reinforcement were observed and discussed carefully and in detail. Then, the calculation methods for predicting the residual values were given. Details of this study are summarized as follows:

(1) With the experimental test of an inverted specimen, four stages are defined for the overall process of crack developing according to development laws of the average crack spacing, the number of through cracks, and crack width. The average crack spacing and the number of through cracks remained stationary in stages II and III. The width of the major crack increased at a rather rapid speed in stage IV until the beam specimen failed.

(2) Based on the existing model for predicting the residual deflection of composite girders subjected to sagging moment, a calculation method for evaluating the residual values in hogging moment regions is presented. It was found that the residual deflection accounted for more than $30 \%$ of the static deflection caused by the fatigue upper limit under the monotonic loading, and this proportion will be larger with the increment of repeated cycles.

(3) Based on the calculation method of nonprestressed reinforcement in PPC beams, an analytical model is proposed for the prediction of residual strain of longitudinal reinforcement in the hogging moment regions of composite beams, which accounts for the slip effect of composite beams and fatigue properties of stud and reinforcement. In stage II $(0.1<n$ / $N<0.9$ ), the model showed a close correlation with the experimental results. The design recommendations for fatigue deformation in hogging moment regions of steel-concrete composite bridges were proposed.

\section{Data Availability}

The data used to support the findings of this study are obtained directly from the tests and included within the article.

\section{Conflicts of Interest}

The authors declare that they have no conflicts of interest.

\section{Acknowledgments}

This research was sponsored by the National Natural Science Foundation of China under project no. 51878151.

\section{References}

[1] Y. Liu, Q. Zhang, Y. Bao, and Y. Bu, "Fatigue behavior of orthotropic composite deck integrating steel and engineered cementitious composite," Engineering Structures, vol. 220, Article ID 111017, 2020.

[2] J. Liu, F.-X. Ding, X.-M. Liu, Z.-W. Yu, Z. Tan, and J.-W. Huang, "Flexural capacity of steel-concrete composite beams under hogging moment," Advances in Civil Engineering, vol. 2019, Article ID 3453274, 13 pages, 2019.

[3] Y. Liu, Q. Zhang, W. Meng, Y. Bao, and Y. Bu, "Transverse fatigue behavior of steel-UHPC composite deck with largesize U-ribs," Engineering Structures, vol. 180, pp. 388-399, 2019.

[4] C.-S. Shim and S.-P. Chang, "Cracking of continuous composite beams with precast decks," Journal of Constructional Steel Research, vol. 59, no. 2, pp. 201-214, 2003.

[5] H.-K. Ryu, S.-P. Chang, Y.-J. Kim, and B.-S. Kim, "Crack control of a steel and concrete composite plate girder with prefabricated slabs under hogging moments," Engineering Structures, vol. 27, no. 11, pp. 1613-1624, 2005.

[6] J. He, Y. Liu, A. Chen, and T. Yoda, "Experimental study on inelastic mechanical behaviour of composite girders under hogging moment," Journal of Constructional Steel Research, vol. 66, no. 1, pp. 37-52, 2010.

[7] Q.-T. Su, G.-T. Yang, and C. Wu, "Experimental investigation on inelastic behavior of composite box girder under negative moment," International Journal Of Steel Structures, vol. 12, no. 1, pp. 71-84, 2012.

[8] Q. Sun, Y. Yang, J. Fan, Y. Zhang, and Y. Bai, "Effect of longitudinal reinforcement and prestressing on stiffness of composite beams under hogging moments," Journal of Constructional Steel Research, vol. 100, no. 13, pp. 1-11, 2014. 
[9] Z. Zhang, J.-C. Liu, X. Xu, and L. Yuan, "Effect of sub-elevated temperature on mechanical properties of ECC with different fly ash contents," Construction and Building Materials, vol. 262, Article ID 120096, 2020.

[10] Z. Zhang, F. Qin, H. Ma, and L. Xu, "Tailoring an impact resistant engineered cementitious composite (ECC) by incorporation of crumb rubber," Construction and Building Materials, vol. 262, Article ID 120116, 2020.

[11] Z. Zhang, F. Yang, J.-C. Liu, and S. Wang, "Eco-friendly high strength, high ductility engineered cementitious composites (ECC) with substitution of fly ash by rice husk ash," Cement and Concrete Research, vol. 137, Article ID 106200, 2020.

[12] H. Ma and Z. Zhang, "Paving an engineered cementitious composite (ECC) overlay on concrete airfield pavement for reflective cracking resistance," Construction and Building Materials, vol. 252, Article ID 119048, 2020.

[13] A. Song, S. Wan, Z. Jiang, and J. Xu, "Residual deflection analysis in negative moment regions of steel-concrete composite beams under fatigue loading," Construction and Building Materials, vol. 158, pp. 50-60, 2018.

[14] G. Hanswille, M. Porsch, and C. Ustundag, "Resistance of headed studs subjected to fatigue loading Part II: analytical study," Journal of Constructional Steel Research, vol. 63, no. 4, pp. 485-493, 2007.

[15] Y. H. Wang, J. G. Nie, and J. J. Li, "Study on fatigue property of steel-concrete composite beams and studs," Journal of Constructional Steel Research, vol. 94, pp. 1-10, 2014.

[16] G. Hanswille, M. Porsch, and C. Ustundag, "Resistance of headed studs subjected to fatigue loading," Journal of Constructional Steel Research, vol. 63, no. 4, pp. 475-484, 2007.

[17] B. Wang, Q. Huang, and X. Liu, "Deterioration in strength of studs based on two-parameter fatigue failure criterion," Steel and Composite Structures, vol. 23, no. 2, pp. 239-250, 2017.

[18] J. S. Fan and J. G. Nie, "Effects of slips on load-carrying capacity of composite beams under negative bending," Engineering Mechanics, vol. 22, no. 3, pp. 177-182, 2005, in Chinese.

[19] J. Han, Y. Song, L. Wang, and S. Song, "Residual strain analysis of non-prestressed reinforcement in PPC beams under fatigue loading," Materials and Structures, vol. 48, no. 6, pp. 1785-1802, 2015.

[20] P. Y. Lv, Y. P. Song, and Q. B. Li, "Fatigue tests and damage model of concrete under axial tension," Journal of Hydraulic Engineering, vol. 33, no. 12, pp. 79-84, 2002, in Chinese. 